\title{
Thermodynamic Analysis of Single Effect Vapor Absorption Refrigeration Cycle
}

\author{
Md. Meraj ${ }^{1}$, Dr. M. Emran Khan ${ }^{2}$, Rashid Imam $^{3}$ \\ ${ }^{1}$ Ph.D., Department of Mechanical Engg., F/o Engg. \& Tech, Jamia Millia Islamia, New Delhi-110025, India \\ ${ }^{2}$ Professor, Department of Mechanical Engg., F/o Engg. \& Tech, Jamia Millia Islamia, New Delhi-110025, India
}

${ }^{3}$ Asst. Prof., Department of Mechanical Engg., Partap Inst. of Tech. \& Science, Akhaipura, N.H.-11, Dist.-Sikar, Rajasthan-332402, India

\begin{abstract}
Present day utilization of low grade energy like solar energy, geothermal energy, waste heat from industries etc. are a challenge. Vapor absorption refrigeration (VAR) cycle is a best alternative to vapor compression refrigeration (VCR) cycle, despite of having low coefficient of performance compared to VCR because it is heat operated. In this paper the energetic and exergetic analysis of single effect vapor absorption refrigeration cycle using the $\mathrm{LiBr}_{2}-\mathrm{H}_{2} \mathrm{O}$ solution as working fluid is done. This analysis is done for the evaporator temperature of $5,7.5,10$ and $12.5{ }^{\circ} \mathrm{C}$ and the main condenser temperature of 30 and $35^{\circ} \mathrm{C}$. The absorber temperature is assumed to be equal to condenser temperature. The calculated results indicate that the value of maximum value of coefficient of performance and maximum exergetic efficiency comes out to be 0.8055 to 0.8849 and 0.3062 to 0.5116 respectively. Exergy destruction is highest in absorber on comparison with other component.
\end{abstract}

Keywords: Vapor absorption refrigeration cycle, Energetic and exergetic analysis, $\mathrm{LiBr}_{2}-\mathrm{H}_{2} \mathrm{O}$.

\section{Introduction}

In present day, with increasing population of the world, the energy utilization is also increasing proportionally. The rate at which the non-renewable source of energy is being consumed becomes a major concern. The Future prospects of the conventional sources of energy like coal, natural gas, petroleum product etc. are to be in scare. This energy crisis has forced the scientists and engineers to come up with ideas of energy efficient system.

Vapor absorption refrigeration system is the best idea regarding to cope up with energy crisis because this system is heat operated, due to which this system can be operated by using low grade of energy like solar energy, geothermal energy, waste heat from industries, etc. This technology has become increasingly popular because it uses natural substances as working fluid in pair of refrigerant and absorbent like $\mathrm{H}_{2} \mathrm{O}-\mathrm{NH}_{3}, \mathrm{LiBr}_{2}-\mathrm{H}_{2} \mathrm{O}, \mathrm{LiNO}_{3}-\mathrm{NH}_{3}, \mathrm{NaSCN}-$ $\mathrm{NH}_{3}$ [1,2,3] etc. which do not cause global warming and ozone depletion. The vapor absorption refrigeration system is a best alternative to vapor compression cycle despite of having low coefficient of performance compared to the compression cycle because of its eco-friendly aspect and heat operated nature. Absorption system is slightly different from compression system. The main constructional difference is that in the compression system, the compressor is used to create a pressure difference, whereas in absorption system the compressor is replaced by absorber-pump-solution heat exchanger-generator assembly, which creates desired pressure differences.

Vapor absorption refrigeration came into existence much earlier dated back to around eighteen centuries. It was used to produce ice by evaporation of pure water from an evacuated container in the presence of sulphuric acid because they have a great affinity. This technology further improved by many researchers like John Lesil, Windhausn etc. This concept was further modified by a Frenchman Ferdinand Carre in 1859, in which he introduced an aqueous-ammonia absorption refrigeration system and patented it. In 1950's, a single effect absorption cycle using aqueous-Lithium Bromide as invented. Many literatures related to this system are available both experimentally and theoretically [4,5]

A number of researchers have performed energy and exergy analysis of absorption refrigeration system. Talbi and Agnew [6], Lee and Sherif [7], Kilic and Kaynakli[8] and Kaynakli and Yamankaradeniz [9] performed a thermodynamic analysis of a single effect vapor absorption system. However, some relative works on double effect vapor absorption refrigeration system considering the analysis of the first law of thermodynamics and the second law of thermodynamics are available $[10,11,12]$.

The purpose of this paper is to provide basic understanding of variation of performance parameter like coefficient of performance, exergetic efficiency and exergy destruction with operating parameter like evaporator and condenser temperature of single effect vapor absorption cycle, which helps in optimization. The effect of evaporator and condenser temperature on coefficient of performance and exergetic efficiency is investigated.

\section{Cycle Description}

The main components of absorption system consist of evaporator, absorber, generator, condenser and solution heat exchanger [13]. The schematic diagram of a single effect vapor absorption refrigeration cycle is shown in figure-1 on which presented analysis is based. This cycle system consist of evaporator, absorber, pump, pre-heater ( $\mathrm{PH})$, generator, condenser, pre-cooler (PC) and throttle valve (TV) as shown in Fig. 1. The $\mathrm{LiBr}_{2} \mathrm{H}_{2} \mathrm{O}$ pair is used as the working fluid in 


\section{International Journal of Science and Research (IJSR) \\ ISSN (Online): 2319-7064 \\ Index Copernicus Value (2013): 6.14 | Impact Factor (2015): 6.391}

this cycle, where $\mathrm{LiBr}_{2}$ works as absorbent and $\mathrm{H}_{2} \mathrm{O}$ works as refrigerant. There are two pressure levels in this cycle; the generator and condenser operate at high pressure while evaporator and absorber operate at low pressure level.

In the presented cycle system the refrigerant enters the evaporator (state 9) as saturated liquid and leaves (state 1) as saturated vapor thereby producing a cooling effect in the required space. The refrigerant vapor leaving the evaporator is then passed through the pre-cooler (state 1-2) for cooling the condensate liquid refrigerant from the condenser (state 78 ) and enters into absorber (state 2). In the absorber, the refrigerant vapor is absorbed by strong solution from the generator, forming weak or dilute solution of the $\mathrm{LiBr}_{2} \mathrm{H}_{2} \mathrm{O}$ mixture. This weak solution leaves the absorber (state 3 ) and is pumped to the generator (state 5) through the pre-heater (state 4-5). In pre-heater solution is heated before entering the generator by using the heat rejected from the strong solution leaving the generator (state 10). The solution after getting heat in the generator releases pure refrigerant (state 6 ) that flows to the condenser. The remaining strong solution flows down to the absorber through the pre-heater.

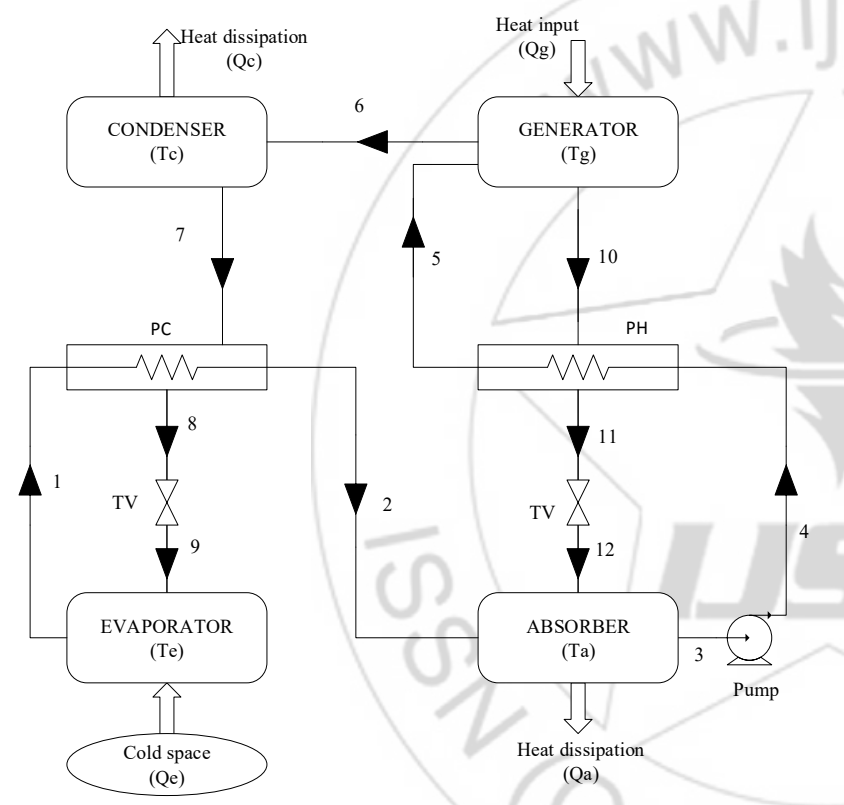

Figure 1. Single effect vapor absorption refrigeration cycle. This improves COP of the system. On the other part, the refrigerant vapor passing through the condenser condenses after rejecting heat to the sink. The condensate refrigerant leaving condenser (state 7) is allowed to pass through the pre-cooler. The condensate refrigerant is throttled through the throttle valve (state 8-9) to reduce it to the evaporator pressure and temperature and enter into the evaporator. Thus, the cycle gets completed.

\section{Thermodynamic Analysis}

The thermodynamic analysis of presenting model is performed by applying the principle of mass conservation, the first law of thermodynamics and the second law of thermodynamics to each component of the cycle. Each component of the cycle is treated as a control volume with inlet and outlet stream of working fluid, heat transfer and work interactions [14].

On the basis of principal of mass conservation, mass balance equation is applied on each component and due to the $\mathrm{LiBr}_{2}$
$\mathrm{H}_{2} \mathrm{O}$ mixture as a working fluid, concentration balance is also applied. They are done by following equation;

Mass Balance:

Concentration Balance:

$$
\sum \boldsymbol{m}_{\boldsymbol{i}}-\sum \boldsymbol{m}_{\boldsymbol{o}}=\mathbf{0}
$$

$$
\sum(m X)_{i}-\sum(m X)_{o}=0
$$

where, $\mathrm{m}$ is the mass flow rate and $\mathrm{X}$ is the mass concentration of $\mathrm{LiBr}_{2}$ in the solution.

On the basis of the first law of thermodynamics, energy analysis is performed on each component of the cycle. This law defines internal energy as state function and gives a formal statement of conservation of energy [14]. The governing equation of energy conservation for steady flow system across each component is as follows:

\section{Energy Balance:}

$$
\sum(\boldsymbol{m h})_{i}-\sum(\boldsymbol{m h})_{o}+\left[\sum \boldsymbol{Q}_{i}-\sum \boldsymbol{Q}_{o}\right] \pm W=0
$$

where, $\mathrm{Q}$ is the rate of heat transfer and $\mathrm{W}$ is the rate of work transfer across component of the cycle.

On the basis of the second law of thermodynamics, exergy analysis is carried out for the system. Second law defines the exergy as a thermodynamic property. In general terms exergy is a measure of work potential or quality of different forms of energy relative to the environmental conditions [15]. Exergy is not simply a thermodynamic property, but it is a property of both a system and surrounding. The Exergy analysis indicates the possibilities thermodynamic improvement of the process under consideration and used in optimization. The governing equation of exergy analysis for steady flow system across each component is as follows:

Exergy Balance:

$$
\sum(m e)_{i}-\sum(m e)_{o}+\sum Q\left(1-\frac{T_{0}}{T}\right) \pm W-E D=0
$$

where, ED is the exergy destruction, $\mathrm{T}_{0}$ is the environment temperature and $\mathrm{e}$ is the exergy which is given by:

$$
\mathbf{e}=\left(\mathbf{h}-\mathbf{h}_{0}\right)-\mathbf{T}_{\mathbf{0}}\left(\mathbf{s}-\mathbf{s}_{0}\right)
$$

where, $\mathrm{s}$ is the entropy and $\mathrm{h}$ is the enthalpy.

The first law and the second law of thermodynamics assists in evaluating the performance of cycle based on energy and exergy respectively. They are coefficient of performance (COP) and exergetic efficiency $\left(\eta_{e x}\right)$, given as follows:

$$
\begin{gathered}
\text { COP }=\frac{Q_{e}}{Q_{g}+W_{p}} \\
\eta_{e x}=\frac{Q_{e}\left|\left(1-\frac{T_{0}}{T_{e}}\right)\right|}{Q_{g}\left(1-\frac{T_{0}}{T_{g}}\right)+W p}
\end{gathered}
$$

where, subscripts e, $\mathrm{g}$ and $\mathrm{p}$ associated with evaporator, generator and pump.

\section{Assumptions}

In order to simplify the energetic and exergetic analysis of single effect vapor absorption refrigeration cycle, several assumptions are made. They are as follows;

1. Analysis is performed under steady state conditions.

2. The refrigerant leaving the evaporator is saturated vapor.

3. The refrigerant leaving the condenser is saturated liquid.

4. The refrigerant at the outlet of generator is superheated vapor.

5. The cycle is operated at two pressure levels.

6. Pressure losses in each component are neglected.

7. The effectiveness of heat exchangers (PH \& $\mathrm{PC})$ is $75 \%$. 


\section{International Journal of Science and Research (IJSR) \\ ISSN (Online): 2319-7064}

Index Copernicus Value (2013): 6.14 | Impact Factor (2015): 6.391

8. For exergy analysis the reference environmental temperature and pressure are $25{ }^{0} \mathrm{C}$ and 1 bar respectively.

\section{Results and Discussion}

The analysis is done for 1 Ton of refrigeration. A computer code has been developed in FORTRAN language to solve a large number of equations simultaneously. The computer code is run in order to determine stream properties at each state point and value of heat and work interaction of all components of the cycle. There are following results of energetic and exergetic analysis of the cycle is presented below in graphical form.

Fig. 2 presents the variation of coefficient of performance (COP) of cycle with generator temperature $\left(\mathrm{T}_{\mathrm{g}}\right)$ at $30{ }^{0} \mathrm{C}$ of condenser temperature for different evaporator temperature $\left(\mathrm{T}_{\mathrm{e}}\right)$. The Figure shows that the coefficient of performance is minimum initially, increases gradually with $\mathrm{T}_{\mathrm{g}}$ up to a certain maximum value and decrease slightly after that. From the figure it is observed that the cycle attains maximum coefficient of performance (COP) i.e. 0.8849 at $60.38{ }^{0} \mathrm{C}$ of generator temperature for $12.5{ }^{\circ} \mathrm{C}$ of evaporator temperature.

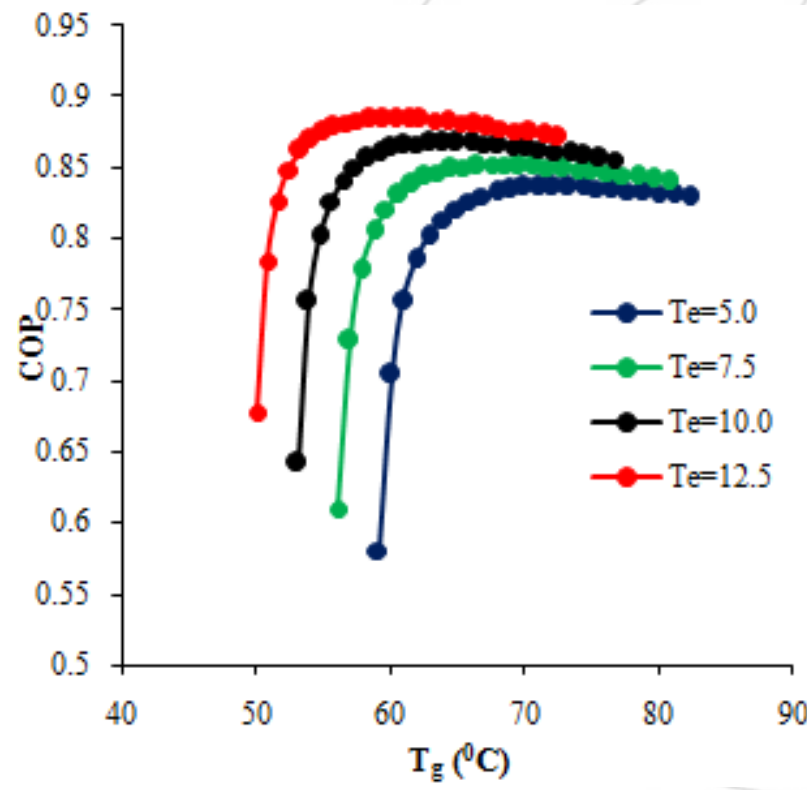

Figure 2: Coefficient of performance v/s Generator temperature at $30{ }^{0} \mathrm{C}$ of condenser temperature.

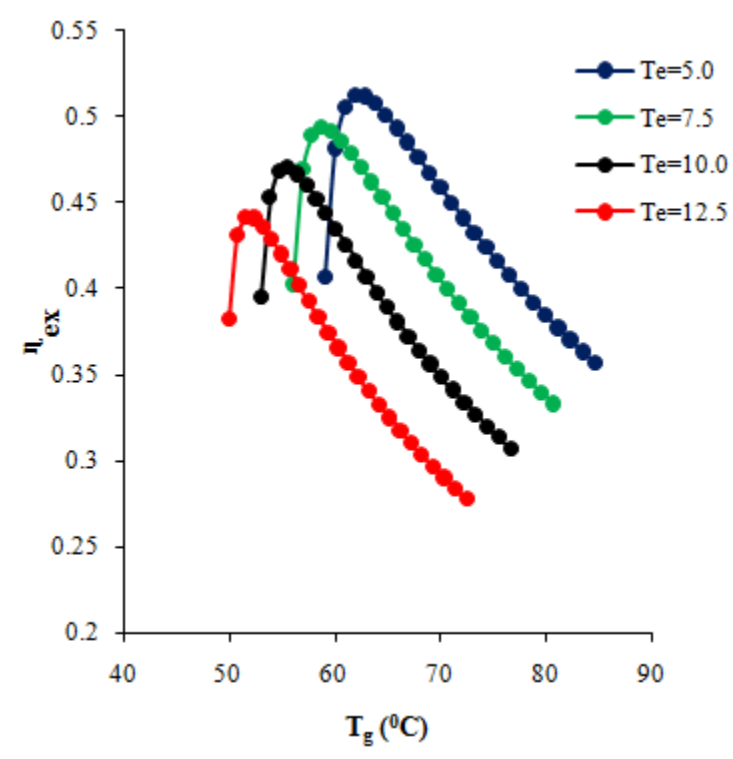

Figure 3: Exergetic efficiency v/s Generator temperature at $30{ }^{0} \mathrm{C}$ of condenser temperature.

$\varpi \mathrm{EDa} \backsim \mathrm{EDg} \backsim \mathrm{EDc} \backsim \mathrm{EDe}$

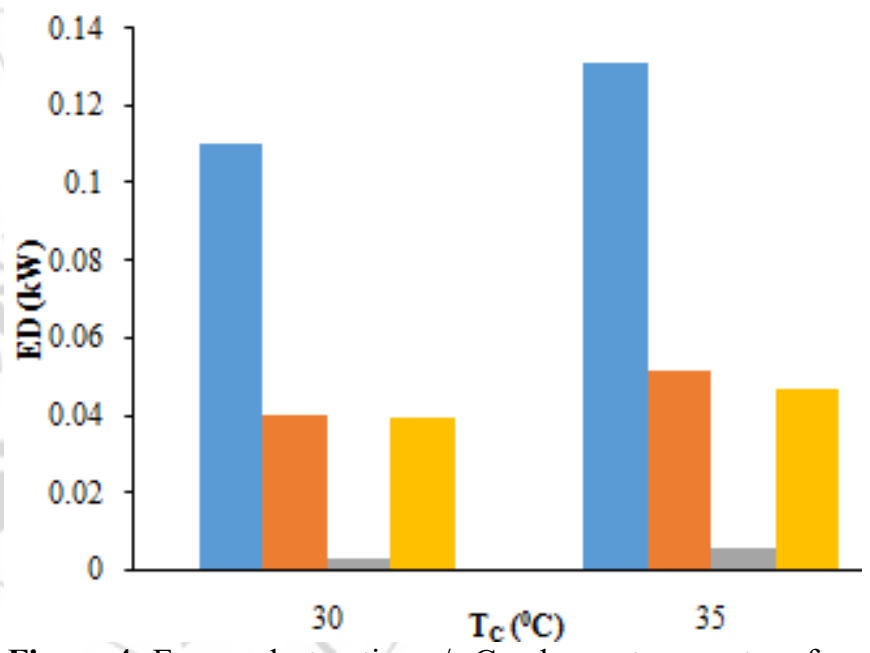

Figure 4: Exergy destruction $\mathrm{v} / \mathrm{s}$ Condenser temperature for different component.

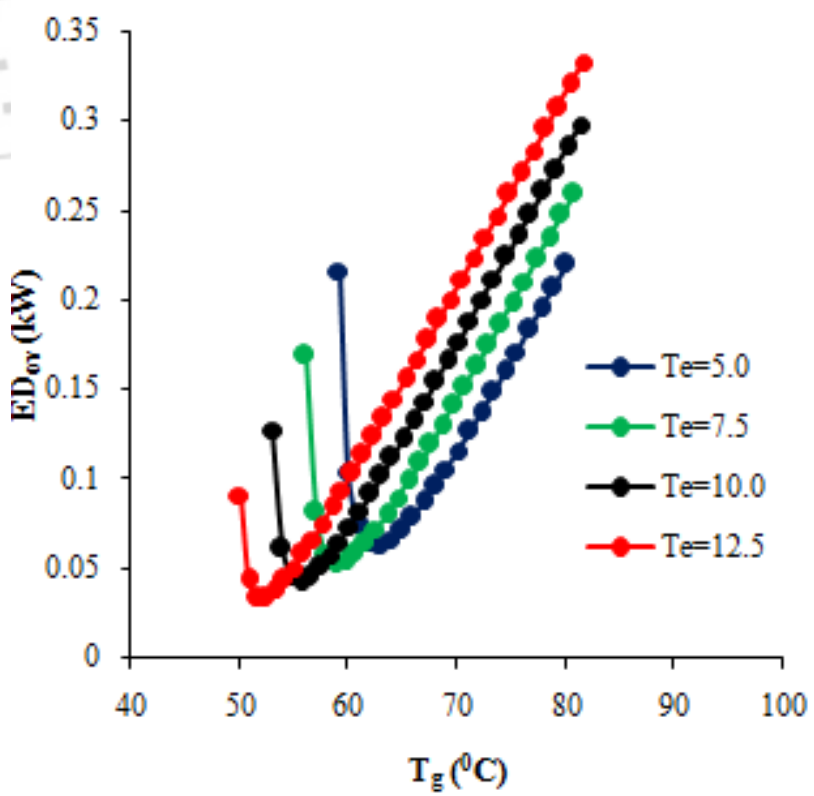

Figure 5: Overall Exergy destruction v/s Generator temperature of cycle at $30{ }^{\circ} \mathrm{C}$ condenser temperature. 


\section{International Journal of Science and Research (IJSR) \\ ISSN (Online): 2319-7064 \\ Index Copernicus Value (2013): 6.14 | Impact Factor (2015): 6.391}

Fig. 3 presents the variation of exegetic efficiency $\left(\eta_{e x}\right)$, of cycle with generator temperature $\left(\mathrm{T}_{\mathrm{g}}\right)$ at $30{ }^{0} \mathrm{C}$ of condenser temperature for different evaporator temperature $\left(\mathrm{T}_{\mathrm{e}}\right)$. The figure shows that the $\eta_{e x}$ is low initially, increases rapidly upto a certain maximum value and decrease gradually with $\mathrm{T}_{\mathrm{g}}$. From the figure it is observed that system attains maximum exergetic efficiency, i.e. 0.5116 at $61.96^{\circ} \mathrm{C}$ of generator temperature for $5{ }^{\circ} \mathrm{C}$ of evaporator temperature.

Fig. 4 represents the variation of exergy destruction (ED) of different components of cycle at different condenser temperature $\left(\mathrm{T}_{\mathrm{c}}\right)$. In the figure, exergy destruction of absorber $\left(E_{\mathrm{a}}\right)$, generator $\left(\mathrm{ED}_{\mathrm{g}}\right)$, condenser $\left(\mathrm{ED}_{\mathrm{c}}\right)$ and evaporator $\left(\mathrm{ED}_{\mathrm{e}}\right)$ are presented at condenser temperature. It is observed that the absorber has maximum exergy destruction.

Figure 5 represents the variation of overall exergy destruction $\left(\mathrm{ED}_{\mathrm{ov}}\right)$ of the cycle with generator temperature $\left(\mathrm{T}_{\mathrm{g}}\right)$ at $30{ }^{0} \mathrm{C}$ of condenser temperature for different evaporator temperature $\left(\mathrm{T}_{\mathrm{e}}\right)$. Overall exergy destruction of the cycle is also known as irreversibility of the cycle. The figure shows that the $\mathrm{ED}_{\mathrm{ov}}$ is higher initially, decreases rapidly upto a certain minimum value and again increases gradually with $\mathrm{T}_{\mathrm{g}}$. From the figure it is observed that system attains minimum $\mathrm{ED}_{\mathrm{ov}}$ i.e. 0.0336 at $52.45{ }^{\circ} \mathrm{C}$ of generator temperature for $12.5^{\circ} \mathrm{C}$ of evaporator temperature.

\section{Conclusions}

There are following conclusions are made from above results and discussion;

- Coefficient of performance and exergetic efficiency of single effect vapor absorption cycle is the sole function of both generator temperature and evaporator temperature.

- The cycle attains maximum coefficient of performance at higher evaporator temperature and moderate generator temperature under operating temperature.

- Exergetic efficiency of the cycle is maximum at low evaporator temperature and moderate generator temperature under operation.

- Absorber has higher exergy destruction compared to other components and overall exergy destruction of the cycle is minimum at upper value of evaporator temperature.

- The maximum value of coefficient of performance and maximum exergetic efficiency come out to be 0.8055 to 0.8849 and 0.3062 to 0.5116 respectively for the cycle.

\section{References}

[1] Siddiqui M.A (1993), "Optimum generator temperature in four absorption cycle using different sources of energy", Energy conversion and management, No.24, pp 251-266.

[2] Saghiruddin, Siddiqui M.A. (1996), "Economic analysis and performance study of three ammonia-absorption cycles using heat recovery absorber", Energy Conversion and Management, No.37, pp 421-432.

[3] Malik I. H., Siddiqui M.A. (1996), "Optimization of generator temperature in the heat operated absorber cycle using four types of aqueous salt solutions", Energy Conversion and Management, No.37, pp 433-445.
[4] Aphornratana S., Eames I.W. (1995), "Thermodynamics analysis of absorption refrigeration cycles using the second law of thermodynamics method", International Journal of Refrigeration; 18:244-452.

[5] Aphornratna S., Sriveerakul T. (2007), "Experimental studies of a single-effect absorption refrigerator using aqueous lithium-bromide: Effect of operating condition to system performance", Experimental Thermal and Fluid Science; 32:658-669.

[6] Talbi MM, Agnew B. (2000), "Exergy analysis: an absorption refrigerator using lithium bromide and water as working fluids", Applied Thermal Engineering; 20:619-630.

[7] Lee F. S., Sherif S.A. (2001), "Thermodynamic analysis of a lithium bromide/water absorption system for cooling and heating applications", International Journal of Refrigeration; 25:1019-1031.

[8] Kaynakli O., Kilic M. (2007), "Theoretical study on the effect of operating conditions on performance of absorption refrigeration system", Energy Conservation Management; 48:599-607.

[9] Kaynakli O., Yamankaradeniz R. (2007), "Thermodynamic analysis of absorption refrigeration system based on entropy generation", Current Science, Vol. 92, No 4, pp 472-479.

[10] Gomri Rabah, Hakimi Riad (2008), "Second law analysis of double effect vapour absorption cooler system", Energy Conversion Management; 49:33433348 .

[11] Kaushik S.C. and Arora A. (2009), "Energy and exergy analysis of single effect and series flow double effect water-lithium bromide absorption refrigeration systems", International Journal of Refrigeration; 32:1247-1258

[12] Mairaj M., Siddiqui S. A., Hafiz A. (2015), "Energetic and exergetic analysis of some models of vapour absorption chillers using lithium bromide and water", Journal of Basic and Applied Engineering Research, Vol. 2, No. 4, pp.326-329.

[13] C.P. Arora "Refrigeration and Air Conditioning", 2008, Tata McGraw Hill Education Private Limited New Delhi.

[14] Cengel Y.A and Boles M.A. "Thermodynamics: an engineering approach", 2008, Tata McGraw Hill Education Private Limited New Delhi.

[15] Ibrahim Dincer, Marc A. Rosen, "Exergy: Energy, Environment and Sustainable Development", 2007, Elsevier.

[16] Patek J, Klomfar J. “A computationally effective formulation of the thermodynamic properties of $\mathrm{LiBr}$ $\mathrm{H}_{2} \mathrm{O}$ solution from 273 to $500 \mathrm{~K}$ over full composition range", International Journal of Refrigeration 2006; 29:566-78.

[17] ASHRAE, ASHRAE handbook: fundamental volume, 1985. 